\title{
A case of photomultiplier tube defect observed in gamma camera DMSA scintigraphy: The importance of regular quality controls
}

\author{
Serdar Sedat Işı1 ${ }^{1,2}[$ \\ ${ }^{1}$ Department of Medical Services and Techniques Nuclear Medicine Techniques Program, Demiroğlu Bilim University Vocational School of \\ Health Services, Istanbul, Turkey \\ ${ }^{2}$ Department of Nuclear Medicine, Demiroğlu Bilim University Şişli Florence Nightingale Hospital, Istanbul, Turkey
}

\begin{abstract}
The most important factor in determining the planar gamma camera image quality is daily quality control studies. There are many external factors that cause degradation in the system's structure and image quality. In this study, we aimed to present the outcomes of photomultiplier tube defect in the double-headed gamma camera with single photon emission computed tomography detector which occurred during daily dimercaptosuccinic acid renal scintigraphy study, which led to changes in the intrinsic homogeneity of the photomultiplier tube, and we emphasized the importance of daily quality control tests in regards to nuclear medicine.

Keywords: Dimercaptosuccinic acid, gamma camera, homogeneity, nuclear medicine, photomultiplier tube defect, quality control.
\end{abstract}

Gamma cameras are devices used to view radiopharmaceutical distribution in the human body (Figure 1). These devices provide information on the physiological and biochemical processes of the patient by detecting the gamma radiation emitted by radioactive materials found within the body. This information is essential in terms of diagnosis of disease, treatment planning, and follow-up. Revealing changes in the imaging system's performance and making necessary arrangements hold great importance in order to acquire accurate clinical information related to disease diagnosis. All of these procedures must be carried out for quality control studies. ${ }^{[1]}$ In case the gamma camera is not properly working, not only is it unable to provide the patient with a beneficial and quality application, the situation may also cause a great deal of harm. It is indicated that a large degree of doctors' success in health services is dependent on working conditions and environment. ${ }^{[2]}$ Gamma cameras, one of the fundamental elements of nuclear medicine imaging, must be regularly tested with quality control procedures. Guidelines have been established by many international institutions to improve the quality control processes and to determine standard practices and acceptance criteria of gamma cameras. Guidelines on the acceptance criteria ${ }^{[3]}$ and routine quality control tests $^{[4]}$ of nuclear medical devices published by the European Association of Nuclear Medicine in recent years comprise important references in this regard.

Ensuring the quality standards for device performance in nuclear medicine applications is highly important. Regular evaluation of gamma

Received: April 24, 2019 Accepted: June 18, 2019 Published online: April 15, 2020

Correspondence: Serdar Sedat Işık. Demiroğlu Bilim Üniversitesi Sağlık Hizmetleri Meslek Yüksekokulu, Tıbbi Hizmetler ve Teknikler Bölümü Nükleer Tıp Teknikleri Önlisans Programı, 34394 Esentepe, Şişli, İstanbul, Türkiye.

Tel: +90 554 - 6243809 e-mail: serdar_sedat_1988@hotmail.com 
cameras, one of the fundamental imaging tools in the field of nuclear medicine is a foremost condition in order to obtain accurate examination results and avoid erroneous findings. Quality control procedures of gamma cameras begin

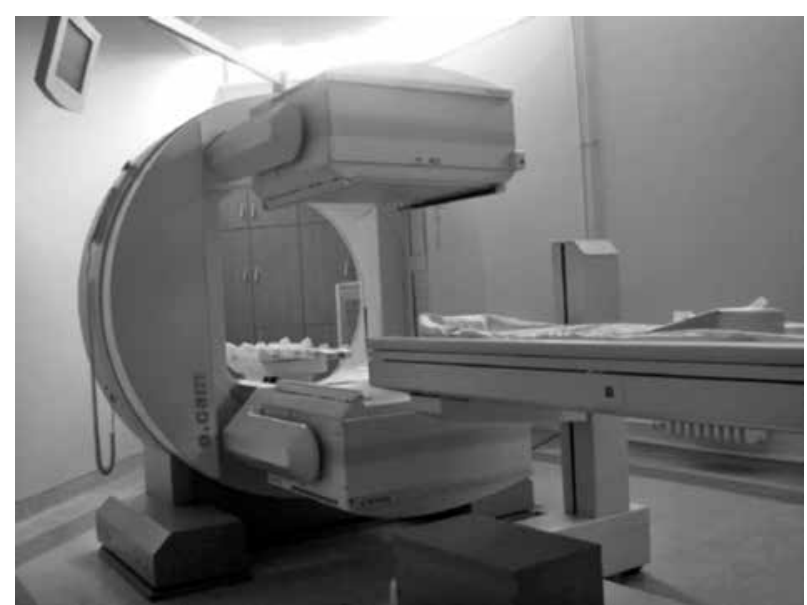

Figure 1. Siemens e-cam brand SPECT dual-head gamma camera.

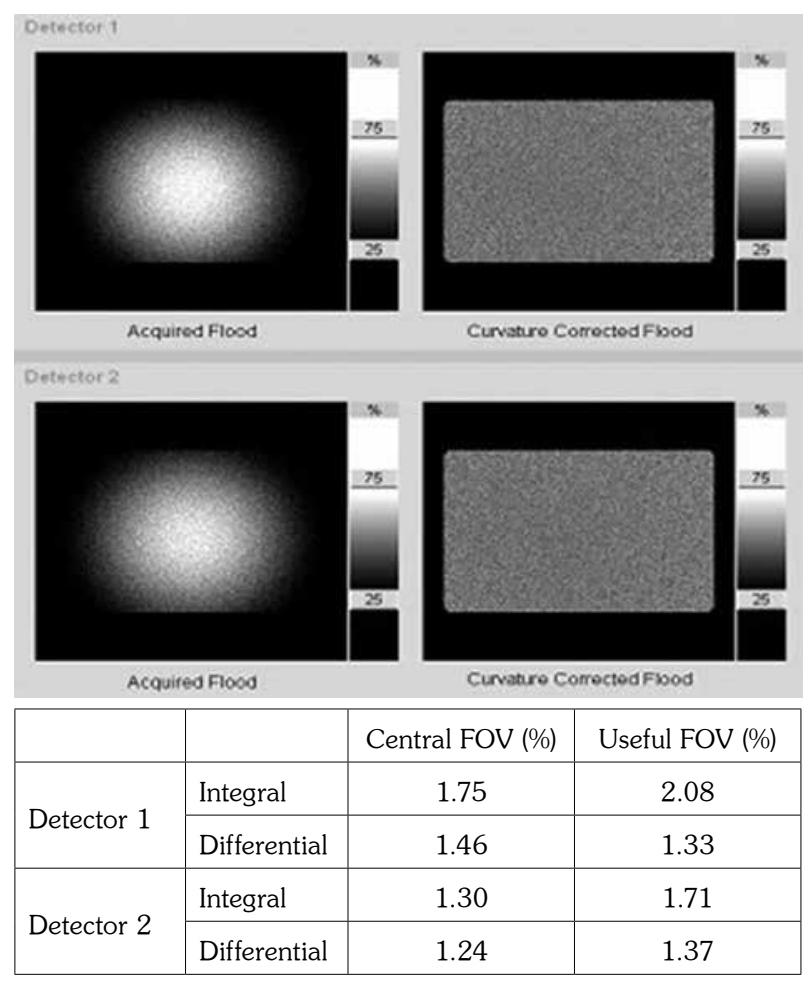

Figure 2. Normal intrinsic homogeneity test with $30,000,000$ counts and valid results before starting daily imaging.

FOV: Field of view. in the installation phase of the devices. The initial control tests performed during installation of the gamma camera are called "acceptance tests". Acceptance tests are notified by manufacturers, provided that they fall within the values determined by international standards. The results obtained in these tests are recorded and the manufacturer then provides results to its customers. The manufacturer then reperforms the acceptance tests, providing the necessary software and phantoms under the control of the supervising medical physician, at the location where the camera is installed. Acceptance tests are expected to comply with the NEMA (National Electrical Manufacturers Association) criteria. ${ }^{[4,5]}$ Although which quality control tests should be applied and how often is addressed in various guideline ${ }^{[4]}$ the quality control procedures that should be applied to each gamma camera vary according to the technical specifications of the camera, method of use, and the environment in which it is used. Taking all of these variables into account, a special quality control program would need to be developed for each gamma camera. The control values obtained after the device's acceptance are compared to the initial standard values. Each quality control value is compared with previous values. Furthermore, recording all quality control test results is significant in terms of detecting changes in camera performance and eliminating problems. ${ }^{[1,6,7]}$

In this case report, photomultiplier tube of detector-1 of a dual-head Single Photon Emission Computed Tomography (SPECT) gamma camera at the Nuclear Medicine department of a

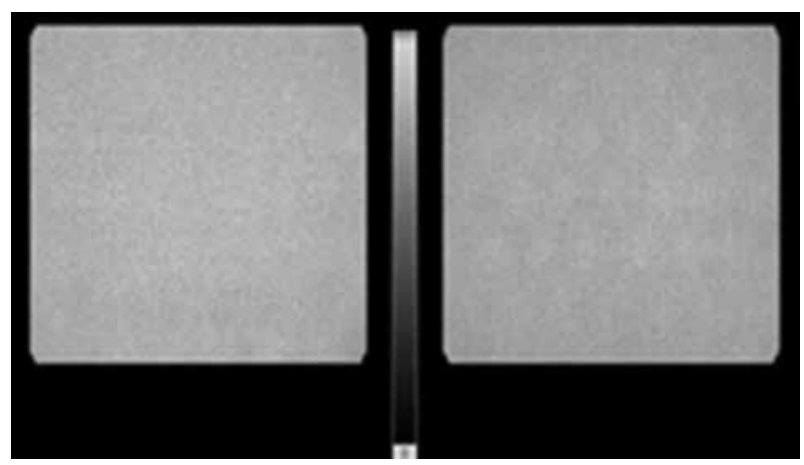

Figure 3. The appearance of extrinsic homogeneity test with 20,000 counts performed on both detectors in order to determine collimator damage, after starting daily imaging following initially normal tests, 
university's medical faculty caused change in the camera's intrinsic homogeneity throughout the day, which reflected in technetium-99m $\left(\mathrm{Tc}^{99 \mathrm{~m}}\right)$ labeled dimercaptosuccinic acid (DMSA) renal cortical scintigraphy and we aimed to present this example in order to emphasize the importance of daily quality control tests in nuclear medicine.

\section{CASE REPORT}

Dimercaptosuccinic acid renal scintigraphy tests were conducted on a day of study in which the daily peaking/tuning tests of the dual-head SPECT gamma camera showed visually and quantitatively normal results (Figure 2 and 3) of intrinsic (useful field of view [UFOV] 2.08\%, central field of view [CFOV] 1.75\%) and extrinsic homogeneity tests, which were conducted before routine procedures at the nuclear medicine department. After patients were administered intravenous DMSA, about 3-4 hours later, anterior- posterior, lateral and oblique spot images of the abdomen were taken at different angles under the gamma camera so that the kidneys entered the visual field. Images taken by the gamma were created by collecting 500,000 counts (photons) for each position. During DMSA static kidney imaging, in the images obtained with detector-1, there was an area that was noticeably reflected on the images and could not be counted in the upper right side of the image, which drew our attention (Figure 4). This error which manifested in images suggested a defect in the photomultiplier tube. As a result, after images of all patients were completed, quality control tests were repeated. Peaking/tuning tests showed that peaking had been performed but tuning process had not. In repeated intrinsic and extrinsic homogeneity testing (Figures 5a-c), there was a prominent tube defect that caused non-homogeneity in detector-1 (Intrinsic: UFOV 99.93\%, CFOV 66.60\%).

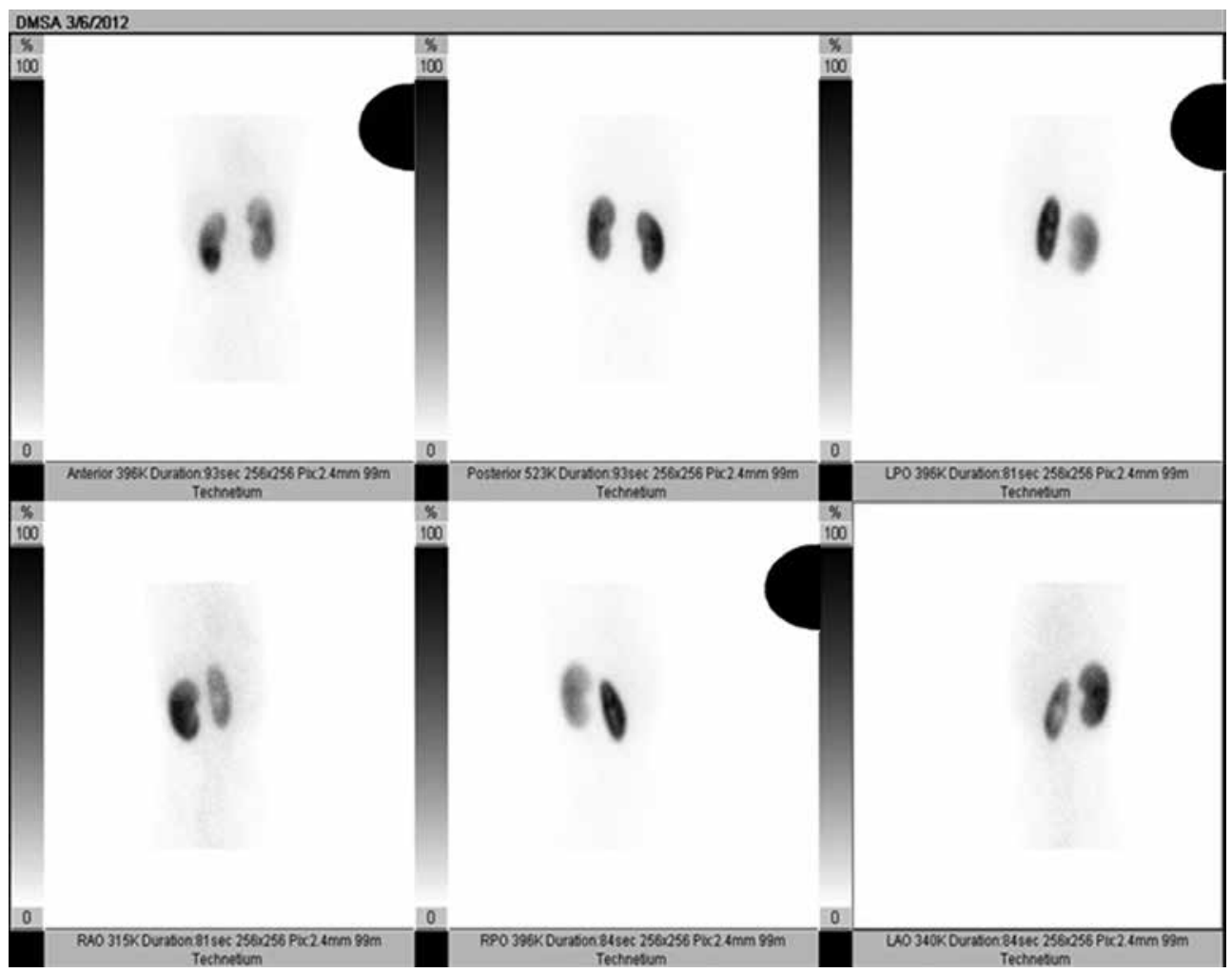

Figure 4. Three hours after $\mathrm{Tc}^{99 \mathrm{~m}}$ dimercaptosuccinic acid injection, images obtained by collecting 500,000 counts (photons) for each detector and position in anterior, posterior, right and left anterior and posterior oblique, right and left lateral imaging of the kidneys under gamma camera. In the images obtained with the number 1 detector, the semi-circular area in the right quadrant that could not be counted suggested photomultiplier defect. 
After the service engineers of the device were notified, certain quality control tests were repeated and confirmed that there was a defect in the photomultiplier tube that was related to the problematic area in the detector. After the source of the problem was identified, the photomultiplier tube was replaced with a new one, peaking/tuning was performed, and the problem
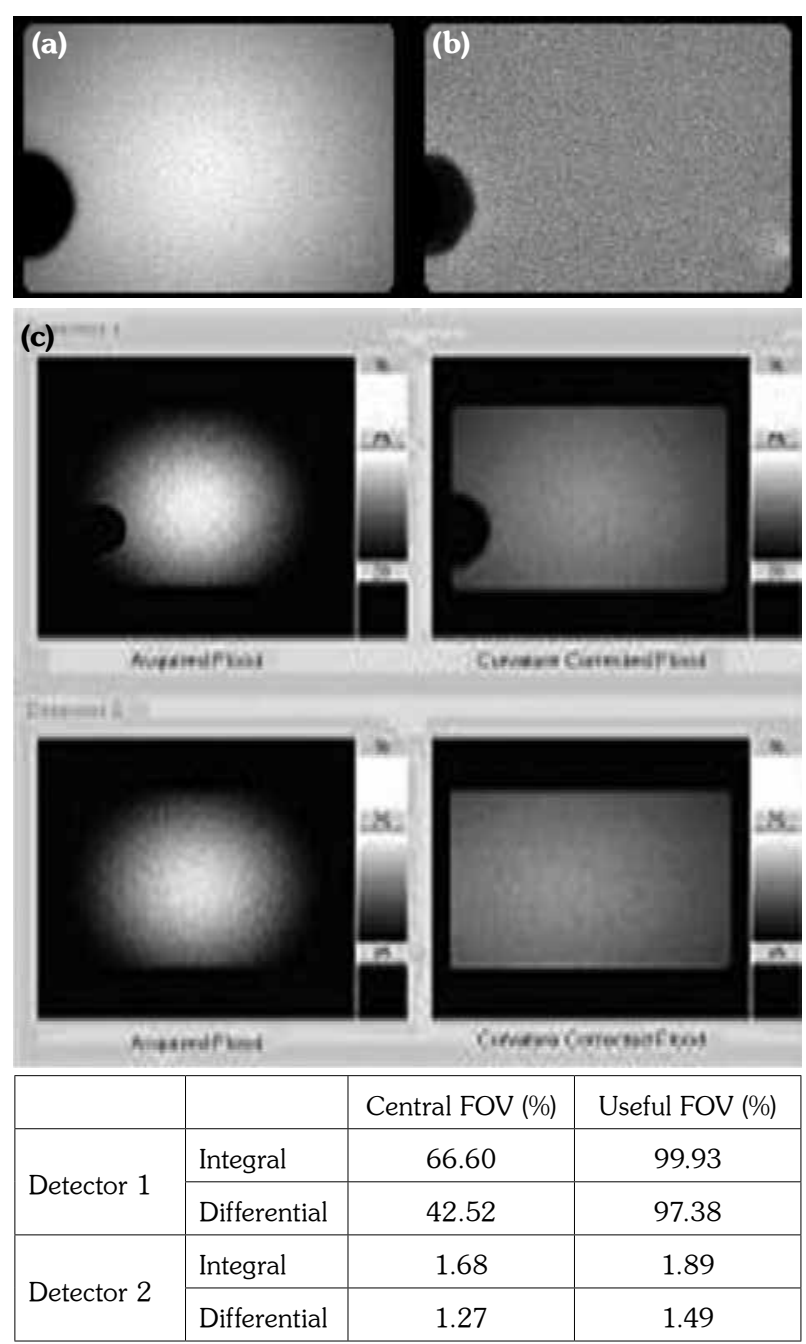

Figure 5. The quality control tests to confirm suspicion of the photomultiplier tube defect: (a) appearance of homogeneity and photomultiplier tube defect as a result of intrinsic homogeneity test with 30,000,000 counts; (b) appearance of homogeneity and photomultiplier tube defect as a result of extrinsic homogeneity test with 5,000 counts with LEHR collimator attached, and (c) image obtained from intrinsic homogeneity test with 30,000,000 counts for each detector (non-homogeneous for detector 1 , homogeneous for detector 2) and quantitative homogeneity values for each detector.

FOV: Field of view. was not re-encountered (Figure 6). After the photomultiplier tube was replaced, intrinsic and extrinsic homogeneity test showed that the nonhomogeneity was corrected and a homogeneous image was obtained (Figure 7a, b).

\section{DISCUSSION}

There are many factors which may cause impaired image quality in the gamma camera system. Basically, the gamma camera system's performance may have low performance with various factors originating from the system's structure or external factors. Certain external factors that may affect the gamma camera system's performance include: collimator damage, time-dependent changes of photon replicator tubes, shift of the energy peak, electronic noise, defects in the crystal and light-permeable layer, contamination on the collimator and surfaces, and magnetic field. Foreign objects on the patient or the patient's movement may also affect the quality of the image. Therefore, changes in the imaging system's performance and external factors may cause undesirable image quality. These changes in the gamma camera's performance may be unnoticed during clinical tests and may be the source of significant error when evaluating images. Therefore, identifying situations that will adversely affect image interpretation with quality control tests before patient imaging is of utmost importance..$^{[1,6-9]}$

This case report presented the circumstances of a photomultiplier tube defect caused intrinsic

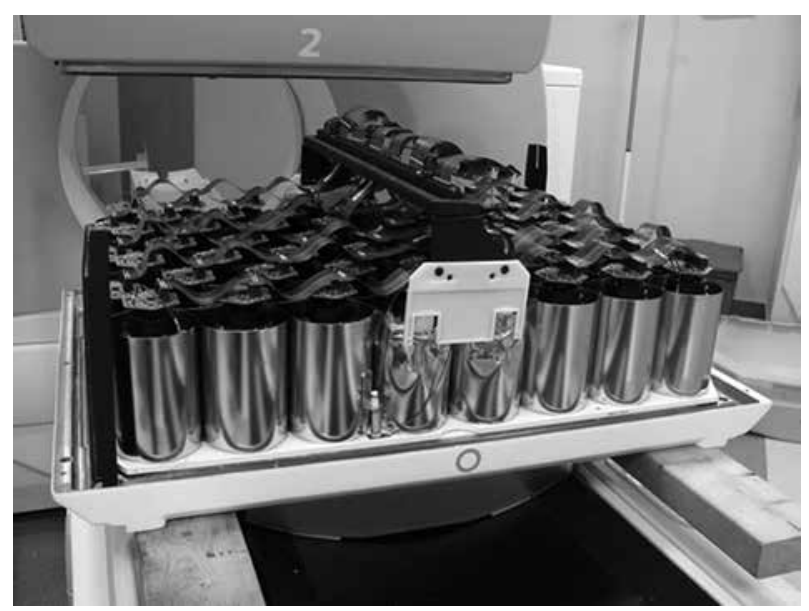

Figure 6. Replacement of the faulty photomultiplier tube of detector 1 with a new one. 
homogeneity changes which reflected in images from detector-1, on a study day with normal daily quality control tests of the dual-head gamma camera system, which were performed before daily admission of patients undergoing DMSA static renal
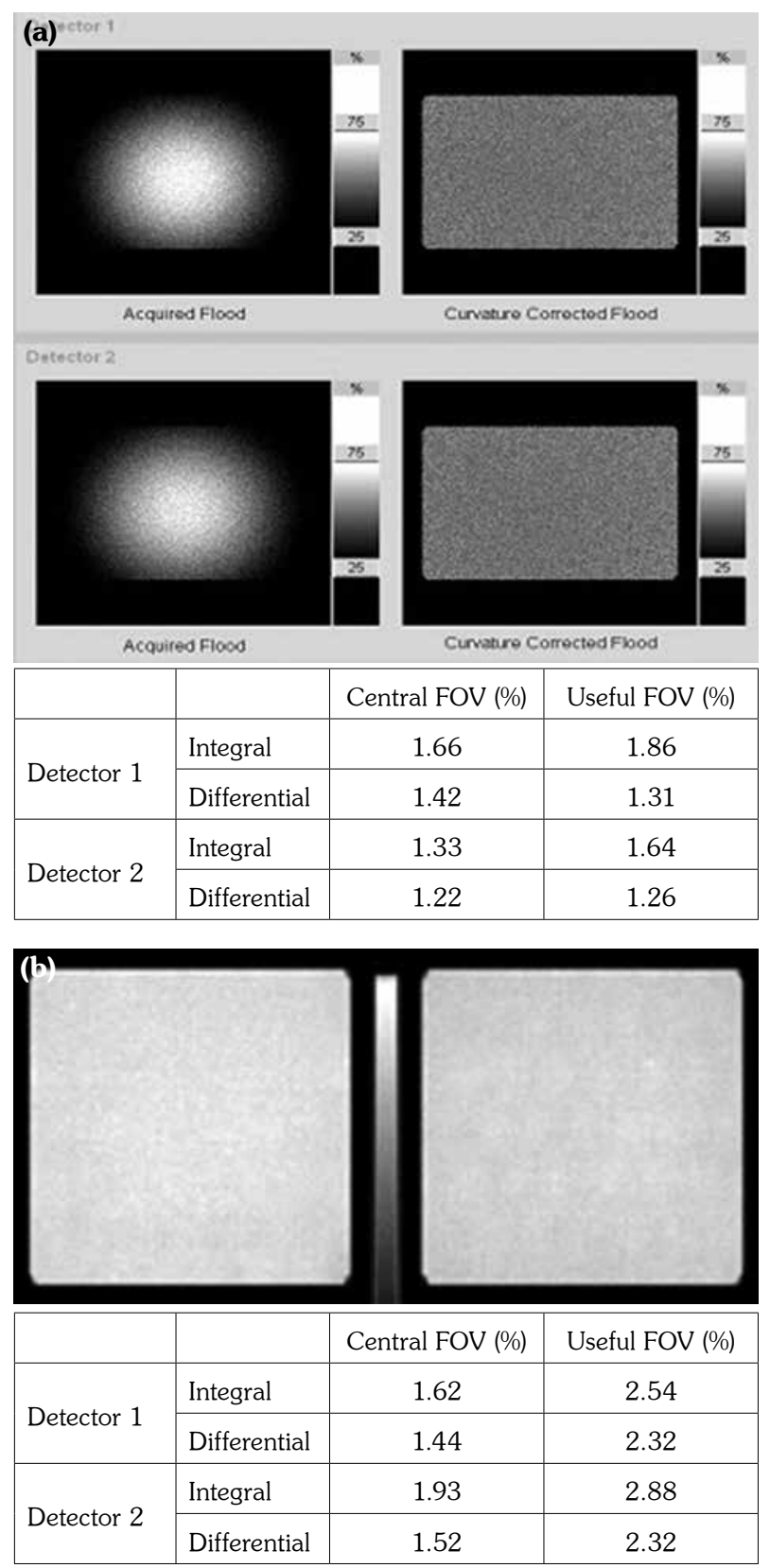

Figure 7. The homogeneity images and quantitative homogeneity results obtained by quality controls performed after replacing the defective photomultiplier tube of detector 1; (a) intrinsic homogeneity study with $30,000,000$ counts; and (b) extrinsic homogeneity study with $120,000,000$ counts when gamma camera detectors were fitted with a low energy high resolution collimator. scintigraphy. Defect related to the photomultiplier in detector-1 of the gamma camera manifested in DMSA static renal imaging, and the detect was identified using simple homogeneity tests.

Before patient admission, $30 \mu \mathrm{Ci} \mathrm{Tc}-{ }^{-99 m}$ control point source was prepared in a plastic dish an intrinsic homogeneity test was performed to collect 30,000,000 counts from both detectors. Results of the intrinsic homogeneity test revealed that the images obtained from both detectors were visually homogeneous, that the quantitative homogeneity values supported the visual results, and the quantitative homogeneity values were between 1.24-2.08\% (Figure 2). At the same time, in order to determine visual detection of collimator damage which may have occurred to the gamma camera when the low energy high resolution (LEHR) collimator was attached as well as determine the homogeneity of the detectors together with the collimator, extrinsic homogeneity test was performed by collecting 20,000 counts from each detector, using planar Co-57 source with 15 millicurie $(\mathrm{mCi})$ activity. According to the visual obtained by the extrinsic homogeneity test, it appeared to be homogeneous and no collimator damage could be distinguished (Figure 3). In the images obtained with the number 1 detector during DMSA kidney imaging in the gamma camera throughout the day, an area that could not be collected on the upper right side of the image which clearly manifested in the images was noticed (Figure 4). When the images were carefully examined, a defect in the photomultiplier which corresponded with the related area came to mind. As a result, after the imaging of the patients was completed, quality control tests were repeated. Homogeneity of the detectors was reassessed with control intrinsic and extrinsic homogeneity tests (Figure $5 \mathrm{a}-\mathrm{c}$ ). By using $30 \mu \mathrm{Ci} \mathrm{Tc}^{-99 m}$ radioactive point source, intrinsic homogeneity test with $30,000,000$ counts of UFOV and CFOV showed that homogeneity values of detector 1 varied between 42.52-99.93\%, that it was not visually homogeneous, and that homogeneity values of detector 2 ranged between $1.27-1.89 \%$ and were visually homogeneous. Quantitative homogeneity values for detector 2 were below the NEMA standard of 2.5-3.5\%. Quantitative homogeneity values for detector 1 were particularly high and passed the NEMA upper limit values (Figure 5c). 
Similarly, when UFOV of detector 1 and detector 2 and the integral and differential homogeneity values within the central field of view corresponding to $75 \%$ of this area were compared for both detectors, the homogeneity values of detector 1 was significantly high compared to detector 2 . This is because, although intrinsic homogeneity images and quantitative homogeneity values of detector 2 were normal and valid, the reason that detector 1 did not have homogeneous appearance and especially high quantitative homogeneity values compared to detector 2 was because there was a defect in the photomultiplier corresponding to the upper left quadrant of the detector. Therefore, quantitative homogeneity values of detector 1 were higher than the quantitative homogeneity values of the number 2 detector, since no counts could be taken in the crescent moon-shaped black area visible in the upper left quadrant of the images corresponding to the photomultiplier tube of detector 1 (Figure 5c). However, in the extrinsic homogeneity test performed with the planar Co-57 source with the LEHR collimator installed in detector 1 , the homogeneity and defect image obtained with 5,000 counts were reconfirmed (Figure 5b).

Although various companies report that corrected homogeneity values can be accepted up to $5 \%$, it should be less than $2.5 \%$ according to NEMA standards. The homogeneity values obtained in the quality control intrinsic homogeneity studies of the gamma camera were very high and similar values were obtained in the repeated homogeneity studies. Since it is known that the acceptable homogeneity values should be maximum $2.5 \%$ and the defect in the photomultiplier tube was identified in detector 1 , the defective photomultiplier tube material was replaced and renewed (Figure 6). According to the results obtained visually and quantitatively in the repeated quality control intrinsic and extrinsic homogeneity tests, the images obtained for each detector were homogeneous, and the quantitative integral and differential homogeneity values were between $1.22-1.86 \%$ for the intrinsic homogeneity test, and between 1.44-2.88 for the extrinsic homogeneity test; these results were found to be within the standards of NEMA and below the specified reference values (Figures 7a, b).
In order to obtain accurate clinical information for the diagnosis of diseases, identifying the alterations in the performance of the imaging system before conducting patient imaging and making the necessary arrangements are of utmost importance for the validity, quality, device, and patients. All procedures are carried out with quality control studies. Regular evaluation of gamma cameras, which is one of the basic tools of imaging in the field of nuclear medicine, with quality control tests is the primary condition for obtaining accurate examination results and avoiding erroneous results. Daily quality control tests on gamma cameras should be performed before the daily work for the continuity of the quality safety of the devices and should be repeated during the day if the homogeneity of the detectors is suspected. In this context, we believe that keeping this case report in mind may be beneficial in raising awareness against problems that may be encountered in clinical applications.

\section{Declaration of conflicting interests}

The author declared no conflicts of interest with respect to the authorship and/or publication of this article.

\section{Funding}

The author received no financial support for the research and/or authorship of this article.

\section{REFERENCES}

1. Değer $M$, Demir M, İnce $M$, Kıraç $S$, Köseoğlu K, Turan E, et al. Kalite Kontrol, Enstrümantasyon ve RadyasyonGüvenliği Komitesi Yönergesi. Turk J Nucl Med 2004; 13:86-101.

2. Lucignani G, Del Sole A. Nuclear medicine: what kind of quality would we want if we were the patient? Eur J Nucl Med Mol Imaging 2010;37:2194-8.

3. Busemann Sokole E, Plachcínska A, Britten A; EANM Physics Committee. Acceptance testing for nuclear medicine instrumentation. Eur J Nucl Med Mol Imaging 2010;37:672-81.

4. EANM Physics Committee, Busemann Sokole E, Plachcínska A, Britten A; EANM Working Group on Nuclear Medicine Instrumentation Quality Control, Lyra Georgosopoulou M, Tindale W, et al. Routine quality control recommendations for nuclear medicine instrumentation. Eur $\mathrm{J}$ Nucl Med Mol Imaging 2010;37:662-71.

5. Early PJ. Planer imaging. In: Early PJ Sodee $\mathrm{DB}$, editors. Principles and practice of nuclear medicine. 2nd ed. St. Louis: Mosby-Years Book; 1994. p. 251-90. 
6. Vanregemorter J, The gamma camera quality control and quality assurance. European Nuclear Medicine Congress, the book of technologists sessions; 1995.

7. Demir M. Gama kameralarda kalite kontrol testleri. Türkiye Nükleer Tip Dergisi 2001;10:217-27.

8. Işık SS, Özcan Kara P, Kara Gedik, G. Bir gama kameranın kurulumu aşamasında tespit edilen kristal ve fotoçoğaltıcı tüp defektinin birlikteliği. Mersin Üniversitesi Tip Fakültesi Dergisi 2014;15:85-90.

9. Ișsk SS, Kara Gedik G, Özcan Kara P. Hasta hareketinin görüntü kalitesine etkisine dair bir olgu sunumu: Hareket artefaktına bağlı yanıltıcı radyoaktivite tutulumları. Acıbadem Üniversitesi Sağlık Bilimleri Dergisi 2014;5:248-50. 